\title{
Patterns of chronic illness among older patients attending a university hospital in Nigeria
}

\author{
Joel O. Faronbi ${ }^{1,2}$, Iyabo Y. Ademuyiwa ${ }^{3}$ and Adenike A. Olaogun ${ }^{1}$ \\ Ghana Med J 2020; 54(1): 42-47 DOI: http://dx.doi.org/10.4314/gmj.v54i1.7
}

\author{
${ }^{1}$ Department of Nursing Science, College of Health Sciences, Obafemi Awolowo University, Ile-Ife, Nigeria \\ ${ }^{2}$ The Frail Elderly Research Support Group (FRESH), Institute of Neuroscience and Physiology, The \\ Sahlgrenska Academy at Gothenburg University, Gothenburg, Sweden. \\ ${ }^{3}$ Department of Nursing Science, Faculty of Clinical Sciences, University of Lagos, Idi-Araba Lagos, Nigeria
}

Corresponding author: Joel O. Faronbi

Conflict of interest: None declared

E-mail:faronbiy2k@yahoo.co.uk, jfaronbi@cartafrica.org

\begin{abstract}
SUMMARY
Background: The rising burden of chronic diseases has attracted the attention of public health researchers and policymakers worldwide.

Objectives: To assess the demographic, morbidity and outcome patterns of chronic illness among the older patients at Obafemi Awolowo University Teaching Hospitals Complex, Ile-Ife, Nigeria.

Design: Retrospective study

Setting: Obafemi Awolowo University Teaching Hospitals Complex, Ile-Ife, Nigeria.

Participants: Seven hundred and eighty-eight (788) adults (60 years and over) hospitalized between 2010 and 2014 in the hospital.

Interventions: None

Results: The age of the selected study population ranged from 60 to 99 years with a mean of $76.08( \pm 10.42)$. More than half $(53.0 \%)$ were between 60-69 years, with a subsequent decline. Male patients accounted for $64.0 \%$, but females were more frequent among patients 80 years and older. The most common health conditions were heart diseases $(22.5 \%)$, neoplasm (13.2\%), cerebrovascular accident (12.4\%), and gastrointestinal diseases (14.5\%). The records showed that $14.9 \%$ were referred to other institution for various reasons (including further management, lack of space, industrial action by workers, discharged against medical advice or dead).

Conclusion: Heart diseases were the major chronic illnesses among the older adults followed by neoplasm conditions, while musculoskeletal conditions were the least. It also found that there was a poor outcome of conditions among older adults in this setting. Therefore, efforts should be made towards the prevention and reduction of chronic illnesses, as well as improving the outcome of care.
\end{abstract}

Keywords: chronic diseases, older adults, health care, retrospective, demographic Funding: Doctoral Fellowship from Consortium for Advanced Research Training in Africa

\section{INTRODUCTION}

The rising burden of chronic diseases has attracted the attention of public health researchers and policy-makers worldwide. Estimates indicate that chronic diseases would account for 41 million deaths globally in 2015 . $^{1}$ Reddy, Shah, Varghese, Ramadoss ${ }^{2}$ declared that a high burden of the chronic condition in low and middle-income countries (LMIC), where over $80 \%$ of deaths from chronic diseases occur. Recent studies also report a high burden of chronic conditions and risk factors among the urban poor in LMIC, as well as in developed countries., ${ }^{3,4}$
For the developed nations, chronic diseases may be a result of lifestyle changes, the urbanisation, and $\operatorname{diet}^{5}$, while in the developing nations, it may result from malnutrition and infection. Even though the nature of chronic illness may be similar, its impact may not be the same in different parts of the world. The impact is worse in LMIC where access to technological advancement for prompt diagnosis and treatment are restricted. In developed nations patients usually can cope better with chronic illnesses, as compared to developing countries. Besides, some diseases that may progress into chronicity are identified and controlled earlier enough, thus reducing the magnitude and overall burden of these illnesses. 
Chronic illness occurs in more than half of the American. ${ }^{6}$ A similar finding also observed among the Chinese population and the prevalence increases with age. ${ }^{7}$ Phaswana-Mafuya, Peltzer, Chirinda, Musekiwa, Kose $^{8}$ also reported that about $50 \%$ of the South African population had at least one chronic non-communicable disease. The most prevalent self-reported chronic non-communicable diseases (NCDs) were hypertension and arthritis. In Nigeria, a study conducted by Abdulraheem, Oladipo, $\mathrm{Amodu}^{9}$ also reported the occurrence of chronic illness in $64.9 \%$ of Nigeria population.

Even though diseases can affect anybody irrespective of age, chronic illness is more common among older adults. CDC reported that about 133 million Americans - nearly 1 in 2 adults - live with at least one chronic disease and results into 7 in 10 deaths each year in the United States. ${ }^{10}$ Chronic diseases are major contributors to health care costs. It drains the finance of people and makes them economically dependent. Apart from massive health care expenditure, the recurrent nature of chronic illness even makes the sufferer unable and unfit for work and increases the level of dependency. Thrall ${ }^{11}$ argued that the medical care costs of people with chronic illnesses represent 75 per cent of the U.S. annual health care spending. Even though the overall cost may not be up to this in Nigeria because of poverty and poor access to medical care, its consequences are worse as evident in morbidity and mortality rate associated with these illnesses.

In developing nations, the magnitude of chronic disease and financial burden could be higher, especially with the emergence and re-emergence of chronic conditions. However, this could be unnoticed as a result of the dearth of data. Schultz, Kopec ${ }^{12}$ argued that chronic medical conditions often present multiple impacts on dimensions of health-related quality of life. The overall health, physical health, mental well-being and ability to function independently may be affected by chronic conditions, although the consequences may vary considerably depending on the particular situation. Chronic diseases may not be curable, their prevalence increases with age, they may occur more within an ageing population and may affect as many as two-thirds of older adults. ${ }^{13}$

This study sought to contribute to current information on management of chronic diseases that are required not only to plan an appropriate geriatric health care service but also to improve the delivery of health care to the older adults.

Findings will further be useful in policy formulation on the prevention of illness and health promotion among the older adults, hence contribute positively to the reduction of morbidity and mortality in Nigeria.
This study assessed the demographic, morbidity and outcome pattern of chronic illnesses among the older adults attending the Obafemi Awolowo University Teaching Hospitals Complex (OAUTHC), Ile-Ife.

\section{METHODS}

In this retrospective study, we extracted and reviewed data from the records of hospitalised patients aged 18 years and older, with chronic illness admitted at OAUTHC Ile-Ife between 2010 and 2014. The sampling included only patients 60 years and above admitted for more than 48 hours. A checklist was used to capture data including age, sex, diagnoses, and indications for admission, intervention, and outcome at discharge.

\section{Data analysis}

Data generated were analysed using descriptive and inferential statistical techniques to estimate the frequency and statistical significance by using chi-square and the analyses were made using the STATA (v12) software.

Ethical approval for the study (ERC2013/11/09) was obtained from the Ethics and Research Committees, Obafemi Awolowo University Teaching Hospitals Complex, Ile-Ife (IRB/IEC/0004553). The head of health information records was informed officially before the commencement of data collection.

\section{RESULTS}

Table 1 presents the total number of files and number of records reviewed from the Obafemi Awolowo University Teaching Hospitals Complex between the year 2010 and 2014. A total of 33280 hospital records were available including outpatients and hospitalized patients of all ages. Some patients had multiple admissions as well as multi-morbidities. Of this figure, 1200 were patients 60 years old and above, and 788 met eligibility for inclusion in the review.

Table 1 Number of records reviewed by year (20102014)

\begin{tabular}{|l|l|l|}
$\begin{array}{r}\text { Year } \\
\text { Total }\end{array}$ & $\begin{array}{l}\text { No of record } \\
\text { reviewed }\end{array}$ \\
\hline $\mathbf{2 0 1 0}$ & 5953 & 137 \\
\hline $\mathbf{2 0 1 1}$ & 7502 & 181 \\
\hline $\mathbf{2 0 1 2}$ & 8177 & 197 \\
\hline $\mathbf{2 0 1 3}$ & 6316 & 149 \\
\hline $\mathbf{2 0 1 4}$ & 5332 & 124 \\
\hline Total & 33280 & 788 \\
\hline
\end{tabular}

Figure 1 shows the hospital admission trends by sex for the years 2010-2014. The study sample included 505 male patients $(64.0 \%)$ and 283 females $(36.0 \%)$. The most common health conditions were heart diseases (22.5\%), neoplasm (13.2\%), cerebrovascular accident (CVA), (12.4\%), and gastrointestinal diseases (14.5\%). 
The records showed that $46.2 \%$ of patients were discharged with a fair or improved condition and $14.9 \%$ referred to other institution for various reasons (including further management, lack of space or industrial action by workers, and discharged against medical advice and dead) (Table 2).

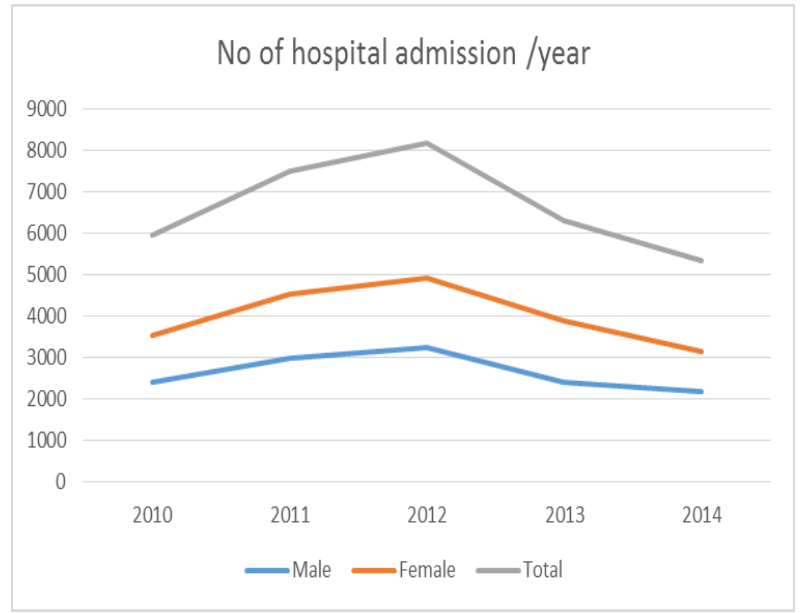

Figure 1 OAUTHC admission by sex and year

Table 2 Diagnosis and outcome of patients admitted between 2010 and 2014

\begin{tabular}{|l|l|}
\hline Variable & $\mathbf{n}(\mathbf{\%})$ \\
\hline Diagnosis (Primary condition) & \\
\hline Heart conditions & $177(22.5)$ \\
\hline Neoplasm & $104(13.2)$ \\
\hline Cerebrovascular accident (CVA) & $98(12.4)$ \\
\hline GIT & $114(14.5)$ \\
\hline Respiratory & $75(9.5)$ \\
\hline Renal condition & $51(6.5)$ \\
\hline Diabetes Mellitus & $44(5.6)$ \\
\hline Musculoskeletal Conditions & $53(6.7)$ \\
\hline Sepsis & $19(2.4)$ \\
\hline Other & $53(6.7)$ \\
\hline Total & $788(100.0)$ \\
\hline Outcome & \\
\hline Discharged home & $364(46.2)$ \\
\hline Dead & $180(22.8)$ \\
\hline DAMA** & $107(13.5)$ \\
\hline Referred & $102(12.9)$ \\
\hline Total & $\mathbf{7 8 8}(\mathbf{1 0 0 . 0})$ \\
\hline Diagnosis
\end{tabular}

Diagnosis (Primary condition) $*=$ There were many with multi morbidity

DAMA $^{* *}=$ Discharged against medical advice

Figure 2 presents the age distributions of the older adults admitted to the hospital between 2010 and 2014. Fiftythree per cent were between 60-69 years old and 35\% from 70-79. In addition, the pattern of chronic illnesses reflects the spread of chronic diseases between sex across the age groups. There was a majority of male across the ages up to the age of 80 and then female predominates.

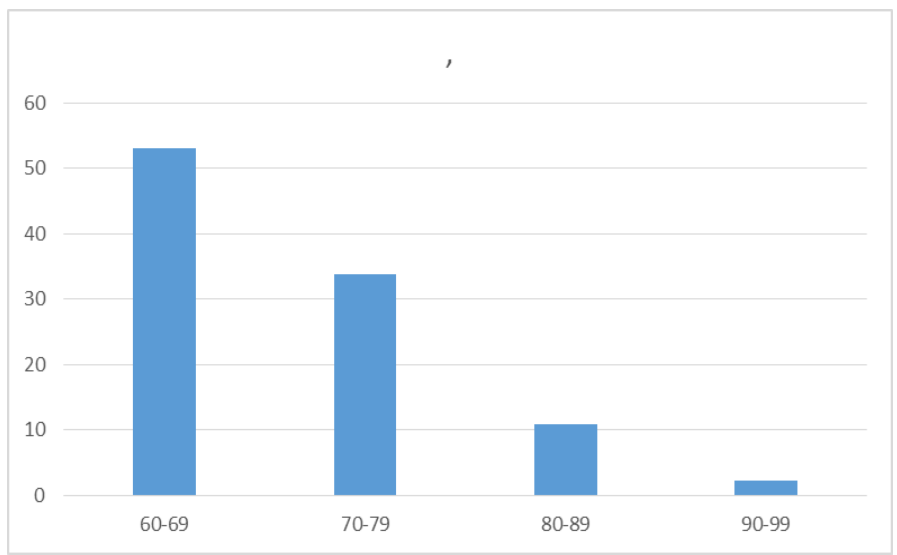

Figure 2 Age distributions of the older people admitted to the hospital

Table 3 presents the outcome of discharge according to the hospitalization diagnosis. Patients with heart conditions $(97 \%)$ and GIT $(89 \%)$ that were discharged with fair condition had a relatively large number. The result also showed that mortality accounts for $22.8 \%$ of the outcome of total admission of the older adults during the period. Among these heart condition, neoplasm, stroke, and GIT conditions account for $25.0 \%, 23.3 \%, 12.8 \%$, and $12.8 \%$ respectively.

Table 3 Outcome of discharge according to diagnosis

\begin{tabular}{|c|c|c|c|c|c|}
\hline Diagnosis & $\begin{array}{l}\text { Discharged } \\
\text { with fair } \\
\text { condition }\end{array}$ & Dead & DAMA & Referred & Total \\
\hline Heart Condition & 97 & 45 & 12 & 23 & 177 \\
\hline Neoplasm & 37 & 42 & 10 & 15 & 104 \\
\hline Stroke & 30 & 23 & 24 & 22 & 99 \\
\hline GIT & 89 & 23 & 16 & 23 & 151 \\
\hline Respiratory & 38 & 6 & 7 & 12 & 63 \\
\hline Renal condition & 18 & 13 & 9 & 11 & 51 \\
\hline Diabetes mellitus & 19 & 8 & 5 & 12 & 44 \\
\hline $\begin{array}{l}\text { Musculoskeletal } \\
\text { conditions }\end{array}$ & 26 & 6 & 8 & 13 & 53 \\
\hline Other & 10 & 14 & 16 & 6 & 46 \\
\hline Total & 364 & 180 & 107 & 137 & 788 \\
\hline
\end{tabular}

\section{DISCUSSION}

The longer life expectancy of the populations led to an increased prevalence of chronic illness in society, and consequently, higher costs for healthcare and nonhealthcare and productivity losses. ${ }^{14}$ One important finding from this study is that a significant number of cases reviewed were discharged against medical advice. This rate is very high compared to the findings of Alfandre ${ }^{15}$ which reported that discharges against medical advice were around $2 \%$ of all hospital discharges. 


\section{Original Article}

Alfandre ${ }^{15}$ further identified some of the causes of discharged against medical advice (DAMA) as due to lower socioeconomic class, male sex, younger age, Medicaid or no insurance, and substance abuse. Hwang ${ }^{16}$ further highlighted that this is more common in hospitals serving disadvantaged inner-city populations, as many as $6 \%$ of general medical patients and $13 \%$ of patients with HIV/AIDS leave Against Medical Advice. The higher rate observed in this study may be due to the fact that the population is worse off compared to those of these previous studies. A previous study among Nigerian older adults showed a high prevalence of chronic illness ${ }^{17}$ and more than half of the adults living with more than one chronic disease. ${ }^{9}$

Findings from the present study further revealed that various chronic illnesses exist among the older people. This supports previous findings ${ }^{18,-20}$ which identified chronic illness such as diabetes, stroke and cardiovascular disease are common among the older adults. Hypertension followed by neoplasm was the leading chronic diseases in the study population. This finding is consistent with the US Centers for Disease Control Prevention ${ }^{21}$ report which identified hypertension and cancer as the leading chronic illness in the United States of America. Although there is a high tendency for people to develop a chronic disease as they age, growing old is not synonymous with chronic diseases. However, old age reduces the ability to resist illness and increases susceptibility to disease. ${ }^{22,23}$

This study population was predominantly male till a certain age, and then the proportion of female surpasses. A possible interpretation is that men are healthier than the women in their old age, or the male is dying earlier than female, or women are more concern about their health and seek medical services for their problem more than men. These questions call for further analysis. The results of this study are consistent with the finding of ${ }^{24}$ which revealed that more than half of the older adult population and almost all hospitalized geriatric patients have comorbid conditions, a condition that is known to be associated with disabilities. ${ }^{25}$

The report from the Medical Expenditure Panel Survey claimed that, in addition to the primary condition, most adults have at least one comorbid chronic disease and as many as $40 \%$ have at least three. ${ }^{26}$ Hypertension is the most prevalent comorbid condition in patients with diabetes. ${ }^{27}$ There is also a correlation between chronic illness and quality of life. Individuals with chronic conditions often tend to have declined health-related quality of life, and the situation may be worse when multiple conditions co-exist. Thommasen, Zhang ${ }^{28}$ opined that the greater the number of co-morbidities, the worse the health-related quality of life in older age.
The total admission declined over the years with the lowest figure in 2014. This decline may not be unconnected with the protracted and incessant industrial action embarked upon by various staff union in the hospital which started in 2013 and took a larger part of the following year. Oleribe ${ }^{29}$ documented that in the previous 36 months to their study, the Nigerian health system has experienced more than eight different strikes involving doctors, nurses and allied healthcare workers. These authors further reiterated that industrial action has a negatively impacted on the healthcare system, leading to several avoidable deaths, complications and outgoing medical tourism.

This study also identified a high mortality rate among the older adults. This is likely to be related to late hospital admission. Most patients often seek for nearby facilities, which may be poorly staffed, and with insufficient equipment and expertise in managing complicated conditions. Patients move from one facility to another before being finally referred for tertiary services. Furthermore, findings from this study revealed that illnesses such as heart condition, neoplasm, stroke, and GIT conditions are the leading cause of high mortality among this population. This may not be unconnected with the fact that these conditions are associated with high mortality especially among the older adults. ${ }^{30,31}$

Similarly, findings from this study showed that stroke has the highest case fatality rate among the population. A similar finding was obtained from an earlier Nigerian study which identified factors contributing to high mortality as absence of first-rate and effective care, cost of care and the perceived belief that stroke is generally a spiritual disease ${ }^{32}$ This is, however, different from a result obtained from Poland where the authors attributed their findings to better management of patients in the acute phase of stroke and implementation of secondary prevention strategies for stroke. ${ }^{33}$ This suggests that prompt and appropriate intervention is necessary for the reduction of stroke fatality.

Even though hospital care suggests an optimum level of attention and satisfaction from patients, these expectations are often let down when they have unmet need. The reason for this may include the nature of chronic illness, as most of the older patients and their relatives are uninformed about their health conditions. They perceived chronic disease to be one of the acute conditions with the expectation that once they are admitted and complete their drug regimen, the illness will disappear. Some situations require referring patients from one hospital to another facility for further management. 
On many occasions, patients and their relatives often request that they should be taken away from the facility thinking that they will approach another facility. This wrong perception calls for quick education about the nature of chronic illness. Besides, some chronic diseases are terminal and often require terminal care. In most of the hospitals in this study environment, there was no facility for managing terminal illness. Terminal cases are handled together with other cases in the long-term facilities and patients and families are not always informed about what the future holds for them. This does generate dissatisfaction as a result of deterioration, as some patients and their relatives decide to discharge against medical advice so that the patients will go home to die.

Failure to identify the persistent and recurrent nature of chronic illness often serves as a barrier to complying with the treatment process. Some patients viewed their illness as an acute one which requires one time management. ${ }^{34}$

One major limitation of this study is inadequate and inaccurate record keeping in the health facility. Some case notes were not available for review. This may be due to missing information about the location of the case notes. The institution, like many others in the country, is still using manual filing and archiving of patient information. The retrospective nature of the study also did not give the opportunity for validation of some of the findings which may have some influence on the generalisability of the findings. However, the study has provided useful information about the outcome of chronic illness in this study setting. These results would be helpful in addressing some of the challenges associated with poor outcome of care in Nigeria.

\section{CONCLUSION}

Prevailing chronic illnesses among older adults include heart failure, diabetes, and the outcome of care of patients with these conditions are poor.

\section{ACKNOWLEDGEMENT}

This research was supported by the Consortium for Advanced Research Training in Africa (CARTA). CARTA is jointly led by the African Population and Health Research Center and the University of the Witwatersrand and funded by the Wellcome Trust (UK) (Grant No: 087547/Z/08/Z), the Department for International Development (DfID) under the Development Partnerships in Higher Education (DelPHE), the Carnegie Corporation of New York (Grant No: B 8606), the Ford Foundation (Grant No: 1100-0399), Google.Org (Grant No: 191994), Sida (Grant No: 54100029), and MacArthur Foundation Grant No: 10-95915-000-INP.

\section{REFERENCES}

1. Strong K, Mathers C, Leeder S, Beaglehole R. Preventing chronic diseases: how many lives can we save? The Lancet. 2005;366(9496):1578-1582.

2. Reddy KS, Shah B, Varghese C, Ramadoss A. Responding to the threat of chronic diseases in India. The Lancet. 2005;366(9498):1744-1749.

3. Nugent R. Chronic diseases in developing countries. Annals of the New York Academy of Sciences. 2008;1136(1):70-79.

4. Mohan V, Mathur P, Deepa R, et al. Urban rural differences in prevalence of self-reported diabetes in India-The WHO-ICMR Indian NCD risk factor surveillance. Diabetes research and clinical practice. 2008;80(1):159-168.

5. Amine E, Baba N, Belhadj M, et al. Diet, nutrition and the prevention of chronic diseases: report of a Joint WHO/FAO Expert Consultation: World Health Organization; 2002.

6. Schneider KM, O'Donnell BE, Dean D. Prevalence of multiple chronic conditions in the United States' Medicare population. Health and quality of life outcomes. 2009; 7(1):82.

7. $\mathrm{Xu} \mathrm{Y}$, Wang L, He J, et al. Prevalence and control of diabetes in Chinese adults. Jama. 2013;310(9):948959.

8. Phaswana-Mafuya N, Peltzer K, Chirinda W, Musekiwa A, Kose Z. Sociodemographic predictors of multiple non-communicable disease risk factors among older adults in South Africa. Global health action. 2013;6(1):20680.

9. Abdulraheem I, Oladipo A, Amodu M. Prevalence and correlates of physical disability and functional limitation among elderly rural population in Nigeria. Journal of aging research. 2011 doi.org/10.4061/2011/369894

10. Centers for Disease Control Prevention. The power of prevention: Chronic disease... the public health challenge of the 21st century. US Department of Health and Human Services. 2009.

11. Thrall JH. Prevalence and Costs of Chronic Disease in a Health Care System Structured for Treatment of Acute Illness 1. Radiology. 2005;235(1):9-12.

12. Schultz SE, Kopec JA. Impact of chronic conditions. Health reports. Aug 2003;14(4):41-53.

13. Wolff JL, Starfield B, Anderson G. Prevalence, expenditures, and complications of multiple chronic conditions in the elderly. Archives of internal medicine. 2002;162(20):2269-2276.

14. Wimo A, Jönsson L, Gustavsson A, et al. The economic impact of dementia in Europe in 2008 - cost estimates from the Eurocode project. International journal of geriatric psychiatry. 2011;26(8):825-832. 
15. Alfandre DJ. "I'm going home": discharges against medical advice. Paper presented at: Mayo Clinic Proceedings, 2009.

16. Hwang, S. W. Case and commentary: discharge against medical advice. Agency for Healthcare Research and Quality. May 2005

17. Faronbi J, Fajemilehin B. Management of osteo-arthritic pain by the elderly in Nigeria. Africa Journal of Nursing and Midwifery 2012.

18. Singh-Manoux A, Guéguen A, Martikainen P, Ferrie J, Marmot M, Shipley M. Self-rated health and mortality: short-and long-term associations in the Whitehall II study. Psychosomatic medicine. 2007;69(2):138-143.

19. World Health Organization. Hand hygiene in outpatient and home-based care and long-term care facilities: a guide to the application of the WHO multimodal hand hygiene improvement strategy and the "My Five Moments For Hand Hygiene" approach: World Health Organization; 2012.

20. Parekh AK, Goodman RA, Gordon C, Koh HK, Conditions HIWoMC. Managing multiple chronic conditions: a strategic framework for improving health outcomes and quality of life. Public health reports. 2011;126(4):460.

21. Centers for Disease Control Prevention. Chronic diseases: the leading causes of death and disability in the United States. Vol 1; 2015: 16.

22. McDonald PE, Zauszniewski JA, Bekhet AK. Cultural comparison of chronic conditions, functional status, and acceptance in older African-American and White adults. Journal of National Black Nurses' Association: JNBNA. 2010;21(1):1.

23. Salive ME. Multimorbidity in older adults. Epidemiologic reviews. 2013;35:75-83

24. Marengoni A, Angleman S, Melis R, et al. Aging with multimorbidity: a systematic review of the literature. Ageing research reviews. 2011;10(4):430439.

25. Quiñones AR, Markwardt S, Botoseneanu A. Multimorbidity combinations and disability in older adults. The Journals of Gerontology Series A:
Biological Sciences and Medical Sciences. 2016;71(6):823-830.

26. Piette JD, Kerr EA. The impact of comorbid chronic conditions on diabetes care. Diabetes care. 2006;29(3):725-731.

27. Tanushi H, Dalianis H, Nilsson G. Calculating prevalence of comorbidity and comorbidity combinations with diabetes in hospital care in Sweden using a health care record database. 2011.

28. Thommasen $\mathrm{H}$, Zhang W. Impact of chronic disease on quality of life in the Bella Coola Valley. Rural Remote Health. 2006;6(2):528.

29. Oleribe OO, Ezieme IP, Oladipo O, Akinola EP, Udofia D, Taylor-Robinson SD. Industrial action by healthcare workers in Nigeria in 2013-2015: an inquiry into causes, consequences and control-a cross-sectional descriptive study. Human Resources for Health. 2016;14(1):46.

30. Raghupathi W, Raghupathi V. An Empirical Study of Chronic Diseases in the United States: A Visual Analytics Approach to Public Health. International journal of environmental research and public health. 2018;15(3):431.

31. Lee SJ, Go AS, Lindquist K, Bertenthal D, Covinsky KE. Chronic conditions and mortality among the oldest old. American journal of public health. 2008;98(7):1209-1214.

32. Ekeh B, Ogunniyi A, Isamade E, Ekrikpo U. Stroke mortality and its predictors in a Nigerian teaching hospital. African health sciences. 2015;15(1):74-80.

33. Sienkiewicz-Jarosz, Halina, Marcin Gtuszkiewicz, Jarosław Pniewski, Maciej Niewada, Anna Członkowska, Charles Wolfe, and Danuta Ryglewicz. "Incidence and case fatality rates of first-ever strokecomparison of data from two prospective population-based studies conducted in Warsaw." Neurologia i neurochirurgia polska. 2011, 45(3) 207-212.

34. Bokhour BG, Cohn ES, Cortés DE, et al. The role of patients' explanatory models and daily-lived experience in hypertension self-management. Journal of general internal medicine. 2012;27(12):1626-1634 